\title{
Aprendizagem ativa conectada em meio ao caos do estudante-ator- rede
}

\author{
Magaly Prado \\ Pós-doutoranda pela Escola de Comunicações e Artes da Universidade de São Paulo. \\ E-mail: magalypprado@gmail.com
}

Resumo: Este artigo traz uma reflexão sobre educação na comunicação. Modelos top-down são postos em discussão e em paulatino desuso desde a chegada da internet. Professores, junto dos alunos, descobrem e atualizam o conhecimento em tempo real, na sala de aula e fora dela - nos chats, nas ruas, no WhatsApp - e compartilham saberes criando laços. Eis apenas dois dos princípios da base deste estudo, o conectivismo, postulado por Siemens (2005): a manutenção de um conhecimento atualizado e rigoroso é o objetivo de todas as atividades de aprendizagem coletivistas; e o fato de que a aprendizagem pode residir em dispositivos não humanos. Conforme sua teoria, além de levar em conta as tendências da aprendizagem, o uso da tecnologia e das redes enfatiza a diminuição da meia-vida do conhecimento. Assim, uma das propostas foi cruzar o pensamento de Siemens com autores como Downes, Brown, Santaella, Mattar, Perniola e Latour, que nos inspiram a aplicar no dia a dia as ações, transcrições, interações com os estudantes de modo a colaborar nesta reflexão.

Palavras-chave: conectivismo; teoria ator-rede; tecnologia social; aprendizagem ativa; interação.
Abstract: This article brings a reflection on education in communication. Topdown models are being debated and have not been used since the internet. Teachers and students discover and update knowledge in real time, within and outside the classroom - in chats, on the streets, on WhatsApp - and share knowledge by creating links. Here are just two of the basic principles of this study: Connectivism, postulated by Siemens (2005): maintaining up-to-date and rigorous knowledge is the goal of all collectivist learning activities and learning can reside in non-human devices. His theory takes into account the tendencies of learning, the use of technology and networks. It also emphasizes the reduction of the half-life of knowledge. Thus, one of the proposals was to compare Siemens' theory to the work of authors such as Downes, Brown, Santaella, Mattar, Perniola and Latour, among others, who inspire us to apply actions, transcriptions and interactions with students in our daily lives, in order to collaborate to this reflection.

Keywords: connectivism; actor-network theory; social technology; active learning; interaction. 
O caos, compreendido como ciência, reconhece a conexão de tudo a tudo, como bem diz George Siemens ${ }^{1}$ ao enfatizar a inclusão de todos a todos. "No tempo, por exemplo, isto se traduz no que é conhecido como o Efeito Borboleta a noção de que uma borboleta que agita o ar hoje em Pequim pode transformar sistemas de tempestade no próximo mês em Nova York" ${ }^{2}$. Esta analogia serve para destacar um verdadeiro desafio: como a "dependência sensível das condições iniciais" afeta de forma profunda o que aprendemos e como agimos com base em nosso aprendizado.

Enquanto a ciência mais tradicional trata de fenômenos supostamente previsíveis, como a gravidade, a eletricidade ou as reações químicas, a Teoria do Caos trata de coisas não-lineares que são efetivamente impossíveis de prever ou controlar, como a turbulência, o clima, o mercado de ações, nossos estados cerebrais e assim por diante. Esses fenômenos são muitas vezes descritos pela matemática fractal, que captura a complexidade infinita da natureza. Um dos princípios do Caos é a imprevisibilidade: porque nunca podemos conhecer todas as condições iniciais de um sistema complexo em detalhes suficientes (ou seja, perfeito), não podemos esperar prever o destino final de um sistema complexo. Mesmo erros ligeiros na medição do estado de um sistema serão amplificados drasticamente, tornando qualquer predição inútil ${ }^{3}$.

Linearidade não pode ser o alicerce para o sistema de educação na era da informação. Nesta fase é fundamental construir modelos com formato não linear que facilitem a aprendizagem. Afinal, aprender e pensar não são proces-

1. SIEMENS, George. Connectivism: Alearning theory for a digital age. International Journal of Instructional Technology and Distance Learning, v. 2, n. 1, 2005. Disponível em: $<$ http://www.itdl.org/Jour nal/Jan_05/article01.htm>. Acesso em: 8 fev. 2015.

2. GLEICK, 1987 apud SIEMENS, op. cit. 2005.

3. FRACTAL FOUNDATION. What is chaos theory? Disponível em: http://fractal foundation.org/resources/ what-is-chaos-theory/.

4. KARTAL apud AKMANSOY, Vesile; KARTAL, Sadik. Chaos theory and its reflections on education: Mehmet Akif Ersoy University case. Educational Sciences: Theory \& Practice, v. 14, n. 2, p. 510-518, 2014.

5. SIEMENS, op. cit.

6. SIEMENS, op. cit., 2005.

7. PERNIOLA, Mario. Do sentir. Tradução de Tom Guerreiro. Lisboa: Editorial Presença, 1999. p. 22. sos lineares; assim, é possível aplicar a teoria do caos aos sistemas complexos de hoje, como as escolas, que fornecem claramente uma oportunidade de mudança e transformação ${ }^{4}$.

A tomada de decisão é indicativa disso e depende das condições. "Se as condições subjacentes utilizadas para tomar decisões mudam, a decisão em si já não é tão correta como era no momento em que foi feita. A capacidade de reconhecer e ajustar-se às mudanças de padrões é uma tarefa-chave de aprendizado" ${ }^{5}$.

Modelos top-down (imposições que seguem a hierarquia do menor para o maior) estão sendo postos em discussão e em paulatino desuso desde a chegada da internet (livre por natureza - por enquanto), que, diga-se de passagem, começou a interagir por troca de mensagens exatamente entre acadêmicos. Professores em conjunto aos alunos descobrem, aumentam e atualizam o conhecimento enquanto ele sucede na sala de aula e fora dela - nos chats das redes, nos encontros nas ruas, nas conversas no WhatsApp - e compartilham saberes, ao mesmo tempo em que criam laços entre eles. "A tecnologia reorganizou o modo como vivemos, como nos comunicamos e como aprendemos" .

Mario Perniola ${ }^{7}$ reflete sobre este tema quando diz que o alheamento (uma espécie de isolamento) "do sentir não consiste em delegar noutros o que deveríamos ser nós a sentir e muito menos na hipótese de algum modelo respeitável nos vir ensinar o modo como devemos sentir". O autor destaca a sensibilidade e a afetividade: 
Se se tratasse simplesmente de um mandar sentir, a estrutura deste não seria alterada: a delegação poderia ser revogada em qualquer momento e nós poderíamos voltar a sentir de modo direto. Na realidade, hoje ninguém parece disposto a delegar a experiência do já sentido noutros: ninguém quer ser excluído da experiência do já sentido! Quanto à presença de modelos que dariam o tom à nossa época, já não existem maîtres à sentir para imitar: o já sentido não pode ser imitado, mas recalcado, repercutido, refletido. No horizonte do sentir alheado não existe já lugar para uma educação sentimental que pouco a pouco ensine a confrontar o mundo interior com a realidade efectual, esta, na verdade, não é algo de racional e de prático, mas é desde logo essencialmente estética, impregnada e embebida de sensibilidade e de afetividade. A realidade virtual contém já todas as possíveis figuras, dimensões e aspectos do científico, é o mapa completo do pays $d u$ tendre, a que cada um nada mais tem a acrescentar, podendo apenas ser atravessado, percorrido; é um repertório exaustivo de sensações e de afetos já sentidos que apenas se pode reproduzir, repetir ${ }^{8}$.

Impossível imaginar que já se estudou tudo ou que a experiência de trabalho basta para acreditar em uma única fonte de saber, o professor. Em tempos de informações velozes e experimentos advindos não somente das redações (o caso do jornalismo), bem como dos portais e sites da internet, das redes, da blogosfera etc., instrutores não cessam de aprender, se assim desejarem.

John Seely Brown ${ }^{9}$ apresenta uma noção interessante de que a internet alavanca os pequenos esforços de muitos com os grandes esforços de poucos. A premissa central é que: "As conexões criadas com nós incomuns suportam e intensificam as atividades de grande esforço existentes. Esta amplificação da aprendizagem, conhecimento e compreensão através da extensão de uma rede pessoal é o epítome do conectivismo"10.

Ao estudarmos o conectivismo - teoria de George Siemens - como um dos pilares da base teórica de atuação desta pesquisadora, podemos trazê-lo neste momento em que corrobora a questão da urgência em se acompanhar a evolução do tempo na educação de acordo com a tecnologia que a cerca e a modifica constantemente. Afinal, o conectivismo apresenta justamente um modelo ${ }^{11}$ de

aprendizagem que reconhece as mudanças tectônicas na sociedade, onde a aprendizagem não é mais uma atividade interna e individualista. Como as pessoas trabalham e funcionam é alterada quando novas ferramentas são utilizadas. O campo da educação tem sido lento para reconhecer tanto o impacto de novas ferramentas de aprendizagem e as mudanças ambientais no que significa aprender ${ }^{12}$.

O aluno cada vez mais tem adquirido uma posição de autonomia no processo de aprendizado. "Na aprendizagem ativa, em oposição à aprendizagem passiva, baseada na transmissão de informação, o aluno assume uma postura mais ativa, na qual ele resolve problemas, desenvolve projetos e, com isto, cria oportunidades para a construção de conhecimento", conforme conceituação de Valente ${ }^{13}$.

A teoria do conectivismo procura detectar as necessidades atuais (das últimas décadas) e proporciona uma visão sobre como adquirir as habilidades necessárias de aprendizagem e as tarefas indispensáveis para que os alunos floresçam em uma
8. Ibidem.

9. Brown fornece o exemplo de um projeto do sistema da Maricopa County Community College que liga os idosos com os alunos da escola primária em um programa de mentor. As crianças "ouvem esses" avós "melhor do que fazem seus próprios pais, a orientação realmente ajuda os professores... os pequenos esforços de muitos - os idosos-complementam os grandes esforços de poucos-os professores". (BROWN, John Seely. Growing up digital: Como as mudanças na web funcionam, educação e as formas de aprendizagem das pessoas. Associação de Ensino a Distância dos Estados Unidos, 2002. Disponível em: <http://www.usdla.org/ $\mathrm{html} /$ journal/FEB02_Issue/ article01.html>).

10. BROWN, op. cit.

11. SIEMENS, op. cit.

12. Ibidem.

13. VALENTE, José Armando: Blended learning e as mudanças no ensino superior: a proposta da sala de aula invertida. Educar em Revista, Curitiba, edição especial, n. 4, p. 79-97, 2014. 
14. BECKER, Beatriz. Vida na mídia: além do jornalismo. Entrevista com Mark Deuze. Revista Eco Pós, v. 1, n. 19, 2016. Disponível em: <https://revistas.ufrj. br/index.php/eco_pos/ article/view/3354/2629>. Acesso em: 12 nov. 2016.

15. Mora, doutor em neurociência pela Universidade de Oxford, professor de Fisiologia Humana da Universidade Complutense, é autor de Neuroeducación. Solo se puede aprender aquello que se ama. MORA, Francisco. "É preciso acabar com o formato das aulas de 50 minutos". Especialista em Neuroeducação aposta na mudança de metodologias, mas pede cautela na aplicação da neurociência na educação. Matéria para o jornal El País, Madri, 23 fev. 2017. Disponível em: <http://brasil.elpais.com/ brasil/2017/02/17/econo $\mathrm{mia} / 1487331225 \_284546$. $\mathrm{html}$. Acesso em: $23 \mathrm{fev}$. 2017.

16. Mora, op. cit.

17. Correa Lima, Manolita. Apresentação na Academia de Professores, Escola Superior de Propaganda e Marketing, São Paulo, 2016.

18. Ibidem. era digital, como, por exemplo, uma metacompetência da exploração de formas de aquisição da informação. Todavia, é importante salientar o que ressalta Mark Deuze: "É quase impossível negar a atividade de mídia nas mãos do indivíduo. Porém, isso não significa que as pessoas sejam automaticamente alfabetizadas quando se trata de mídia, o que é, naturalmente, um desafio da tecnologia e da educação"14.

Para enfrentar esse desafio - de estar com o conhecimento sempre atualizado -, especialmente porque conforme sua teoria, além de levar em conta as tendências da aprendizagem, o uso da tecnologia e das redes enfatiza a questão da redução da duração do tempo de vida do conhecimento até que se torne obsoleto, quando a capacidade de avaliá-lo rapidamente é muito valorizada, eis alguns dos princípios do conectivismo postulados:

- a aprendizagem e o conhecimento repousam numa diversidade de opiniões;

- a aprendizagem é um processo de conectar nós especializados ou fontes de informação;

- a aprendizagem pode residir em dispositivos não humanos;

- a capacidade de saber mais é mais importante do que aquilo que sabemos num determinado momento;

- promover e manter conexões são fundamentais para facilitar a aprendizagem contínua. A capacidade de ver conexões entre ideias, conceitos e áreas de saber é uma competência crucial;

- a manutenção de um conhecimento atualizado e rigoroso é o objetivo de todas as atividades de aprendizagem coletivistas;

- o tomar de decisões é, em si mesmo, um processo de aprendizagem. Escolher o que aprender e o sentido da informação que nos chega é visto através da lente de uma realidade em permanente transformação. A resposta que agora é correta pode ser errada amanhã, devido a alterações no clima informacional que afeta a decisão.

No convívio com os alunos, especialmente os ingressantes em cursos de graduação, a emoção é quem guia. Ao estudar como o cérebro aprende, a neuroeducação dinamita as metodologias tradicionais de ensino. A contribuição mais contundente é "que o cérebro precisa se emocionar para aprender. E não existe ideia inovadora considerada válida que não contenha esse princípio"15 - é o que diz a introdução da entrevista de Menárguez com Francisco Mora, que "recomenda cautela e adverte que na neuroeducação ainda há mais perguntas do que respostas"16.

Sabemos que o tempo dedicado às aulas expositivas não deve durar mais de 20 minutos $^{17}$. Por sua vez, Mora reforça a premissa de encurtar a duração da aula, mas ainda fala em mais que o dobro do tempo quando argumenta que "a educação pode ser transformada para tornar a aprendizagem mais eficaz, por exemplo, reduzindo o tempo das aulas para menos de 50 minutos para que os alunos sejam capazes de manter a atenção"18. 
A neuroeducação transfere a informação de como o cérebro funciona com o aperfeiçoamento dos processos de aprendizagem. Mora afirma ser imprescindível "saber quais estímulos despertam a atenção, que em seguida dá lugar à emoção" ${ }^{19}$, pois sem esses dois fatores não ocorre aprendizagem. É notório que é mais difícil fazer o estudante aprender ou refletir sobre algo se ele não estiver motivado.

É necessário despertar a curiosidade, que é o mecanismo cerebral capaz de detectar a diferença na monotonia diária. Presta-se atenção àquilo que se destaca. O prazeroso. Acender uma emoção no aluno, que é a base mais importante sobre a qual se apoiam os processos de aprendizagem e memória. As emoções servem para armazenar e recordar de uma forma mais eficaz ${ }^{20}$.

O professor deve começar a aula de maneira estimulante; Mora chega a considerar como técnica de ensino para sensibilizar o aluno o uso de imagem chocante e de elemento de provocação, obviamente não no sentido (respectivamente) de ofensa ou insulto, como se costuma entender pelos termos - a intenção é "romper o esquema e sair da monotonia. Sabemos que para um aluno prestar atenção na aula não basta exigir que ele o faça" ${ }^{21}$.

Mora acredita que os elementos desconhecidos, que acabam por nos surpreender, são exatamente aqueles que abrem a janela da atenção; assim, são imprescindíveis para a experiência de quem aprende. Em outra técnica, ele finaliza com a parte de mais difícil compreensão nas metodologias ativas: o autoaprendizado nos desafios para que achem soluções. É complicado porque, na era da velocidade, os estudantes são inquietos, multitarefeiros e ansiosos para resolver e acabar uma tarefa. "O cérebro utiliza todos os seus recursos a cada vez que se depara com a resolução de problemas, com processos de aprendizagem ou de memória" 22 .

Estudantes prestam atenção ao conteúdo quando estão envolvidos emocionalmente, sentem curiosidade no assunto e são estimulados a descobrir e resolver desafios coletivamente. Se houver alguma competição em formato de game, melhor para a aprendizagem embutida. Ao brincar, aprendem. AlbertLászló Barabási ${ }^{23}$ afirma que "os nós sempre competem por conexões porque os links representam a sobrevivência num mundo interconectado”.

Esta competição é em grande parte embotada dentro de uma rede de aprendizagem pessoal, mas a colocação de valor em certos nós sobre os outros é uma realidade. Os nós que adquirem com êxito maior perfil terão mais êxito na aquisição de conexões adicionais. Em um sentido de aprendizagem, a probabilidade de que um conceito de aprendizagem será ligado depende de quão bem ele está atualmente ligado. Nodes (podem ser campos, ideias, comunidades) que se especializam e ganham reconhecimento por seus conhecimentos têm maiores chances de reconhecimento, resultando assim em polinização cruzada de comunidades de aprendizagem ${ }^{24}$.

Assim, "observa-se que os nós não se referem apenas a atores humanos, mas também podem ser bancos de dados, bibliotecas, organizações, ou seja,

19. Ibidem.

20. Ibidem

21. Ibidem.

22. Ibidem

23. BARABÁSI, 2002 apud SIEMENS, op. cit., 2005.

24. Ibidem 
qualquer fonte de informação, o que torna as possibilidades de estabelecer conexões infinitas" ${ }^{25}$.

\section{CURIOSIDADE INTELECTUAL}

No artigo "A morte das ciências humanas vai matar também as exatas - É crucial reconhecer que as descobertas nascem da curiosidade", de James Bank $^{26}$, o mais interessante está no parágrafo final: "As iniciativas educacionais geralmente focam no currículo, mas promover a curiosidade intelectual não é algo facilmente descritível num currículo. Essa tarefa depende da cultura da escola e dos valores dos alunos e dos instrutores" ${ }^{27}$.

Nem todas as instituições dão abertura para a utilização de metodologias ativas.

Pelo menos em suas formas mais simples, os professores conhecem meios de ensinar e aprender que podem ser considerados como um tipo de metodologia ativa, ainda que não sejam rotuladas ou conhecidas por essa expressão. $\mathrm{O}$ ensino por meio de projetos, assim como o ensino por meio da solução de problemas, são exemplos típicos de metodologias ativas de aprendizagem ${ }^{28}$.

De qualquer forma, educadores não deveriam começar a elaborar uma política educacional sem, ao menos, reconhecer que "a próxima revolução tecnológica não virá de pessoas que sempre têm a resposta certa, mas de pessoas cuja aprendizagem as dotou de curiosidade intelectual suficiente para se sentirem à vontade mesmo quando obtêm a resposta errada" ${ }^{29}$. Bank afirma e é taxativo ao raciocinar que

25. Ibidem

26. BANK, James. A morte das ciências humanas vai matar também as exatas. Disponível em: <http:// pt.aleteia.org/2016/01/26/

a-morte-das-cienci as-humanas-vai-matar-tam bem-as-exatas-2/?ru=b 4127 ec0c12e59207195a9b c32e85f72>. Acesso em: 18 set. 2016.

27. BANK, op. cit.

28. BARBOSA, Eduardo Fernandes; MOURA, Dácio Guimarães de. Metodologias ativas de aprendizagem na educação profissional e tecnológica. Boletim Técnico do Senac, Rio de Janeiro, v. 39, n. 2, p.48-67, 2013.

29. BANK, op. cit.

30. Ibidem.

31. PERNIOLA, op. cit.

32. Ibidem educadores e tecnocratas acreditam, erroneamente, que já sabemos ou já pensamos em tudo de que precisamos para o próximo boom econômico ou para a próxima revolução científica e que tudo seria apenas questão de dar à próxima geração as respostas que nós já temos. É menos importante treinar as pessoas para chegarem à próxima fronteira do que educá-las para discernirem quais são as fronteiras que vale a pena $\operatorname{cruzar}^{30}$.

Em síntese, a ideia é incentivar o debate e a discordância, melhorar as habilidades de pensamento crítico dos alunos e sua criatividade. Diferentemente da matemática, diz Bank, "é raro que haja nas artes liberais uma resposta claramente correta. Nunca há uma perspectiva que possa servir indefinidamente. Isto ocorre porque o 'melhor que já foi pensado e dito' foi mudando ao longo do tempo; mais ainda: o mundo foi mudando".

O poder da ideologia e da burocracia baseia-se no alheamento (como um desvario) que conduz para fora de cada um, respectivamente o pensar e o agir, diz Perniola ${ }^{31}$, "mas estes alheamentos revelaram-se insuficientes; a nossa época reclama e exige algo mais: o alheamento do sentir, a sua transferência para o exterior, a sua posição como algo independente, social e coletivo"32.

Não radicalizemos. Mesmo sabendo que existem pessoas que são empreendedoras, muitas vezes realizadas (e assim tinham de ser, para chegar à posição 
que ocupam), Bank, ao se referir aos participantes de um congresso, relata o que diziam os empreendedores: "Mas elas [as pessoas] queriam, essencialmente, treinar a próxima geração para ocupar papéis precisos e para ter o preciso conhecimento que elas próprias tinham" ${ }^{3}$.

$\mathrm{O}$ autor lembra que não é exatamente assim que o mundo funciona e que os problemas de amanhã "são sempre diferentes dos problemas de hoje. As soluções que funcionam hoje não vão responder a todas as questões que surgirão na próxima década. Adaptar-se ao amanhã só é possível a partir do próprio ato de se viver em sociedade" ${ }^{34}$. Já afirmava Siemens em 2004 ${ }^{35}$ : "A nossa capacidade para aprender o que precisamos para amanhã é mais importante do que aquilo que sabemos hoje, e é por isso que o verdadeiro desafio para qualquer teoria da aprendizagem é ativar o conhecimento no ponto de aplicação”.

$\mathrm{Na}$ atualidade, viver socialmente implica estarmos no contexto de convergência, ou mesmo pós-convergência, das mídias e "de navegação pelas arquiteturas líquidas de informação", conforme enfatiza Santaella ${ }^{36}$ : "todo processo educacional é cultural e socialmente sobredeterminado. Isso quer dizer que não há como separar a educação das condições culturais em que ela se desenvolve".

A navegação em paisagens de informações e de conhecimentos, a criação de grupos de trabalho virtuais em escala local, regional, nacional e mundial, as inúmeras formas de interação possíveis entre os cibernautas e seus mundos virtuais criam uma enorme quantidade de comportamentos inovadores que trazem consigo profundas consequências sociais, culturais e educacionais ${ }^{37}$.

Uma realidade em constante transformação amedronta quem acha estar estabilizado e permanece sem encarar a evolução da tecnologia e da vida que se insere nela. Conforme apuração de pesquisa de Mattar ${ }^{38}$, "apesar de alguns autores argumentarem que o conectivismo não deve ser considerado uma nova teoria da aprendizagem" ${ }^{9}$, Downes, outro teórico do conectivismo, propõe:

uma pedagogia baseada em rede e Siemens (2005) discute as limitações do behaviorismo, cognitivismo e construtivismo como teorias de aprendizagem, porque elas não abordariam a aprendizagem que ocorre fora das pessoas (ou seja, que é armazenada e manipulada pela tecnologia) nem a que ocorre nas organizações $^{40}$.

Siemens $^{41}$ arrola alguns dos pontos centrais na sua teoria, entre eles: "Compreensão, coerência, interpretação (sensemaking), significado (meaning): estes elementos são proeminentes no construtivismo, menos no cognitivismo, e estão ausentes no behaviorismo", e aponta que no conectivismo "o fluxo rápido e a abundância de informação elevam estes elementos a um patamar crítico de importância". De acordo com o autor, os conteúdos "que aprendemos têm que ser atualizados, relevantes e contextualmente adequados. A atualidade do
33. BANK, op.cit.

34. Ibidem

35. SIEMENS, 2004.

36. SANTAELLA, Lucia. Curso de especialização em educação na cultura digital. Linguagens do Nosso Tempo. 1. ed. Brasília, DF. MEC, 2014. Disponível em: <http://catalogo.educa caonaculturadigital.mec. gov.br/hypermedia_files/ live/linguagens_do_nos so_tempo/apresentacao. html>. Acesso em: $12 \mathrm{dez}$. 2016

\section{SANTAELLA, op. cit.}

38. MATTAR, João. Aprendizagem em ambientes virtuais. Revista Teccogs, n. 7, jan.-jun., 2013. Disponível em: <http://www.pu csp.br/pos/tidd/teccogs/ artigos/2013/edi cao_7/2-aprendizagem _em_ambientes_virtua is-joao_mattar.pdf >. Acesso em: 17 out. 2016.

39. Os autores analisados por Mattar são Verhagen (2006); Kerr (2007); Kop; Hill (2008); Bell (2011).

40. DOWNES, 2011 apud MATTAR, op. cit.

41. SIEMENS, George. Knowing knowledge, 2006. Disponível em: <http:// www.elearnspace.org/ KnowingKnowledge LowRes.pdf >. Acesso em: 12 mar. 2015. 
42. Siemens reconhece as contribuições originárias das teorias da aprendizagem na formulação do conectivismo: "todas as ideias são herdeiras de outras e todos os conceitos têm raízes". Assim, dentre as principais raízes do conectivismo, encontram-se: a noção de comunidade de prática de Lave Wenger e em certa medida de Papert, que considera a aprendizagem como um fenômeno situado, decorrente da participação em comunidades de prática; a aprendizagem social (construtivismo) de Vygotsky e Bruner; mais recentemente elaborados, o trabalho de Stephen Downes sobre conhecimento conectivo e o conceito de conhecimento rizomático e de comunidade como currículo de Dave Cormier, entre tantas outras referências (SIEMENS, 2008).

43. SIEMENS, 2006, p. 43

44. Ibidem, p. 36.

45. Uma das primeiras contribuições muito importantes de Downes foi precisamente adicionar aos dois tipos tradicionais de conhecimento considerados - o qualitativo e o quantitativo - um terceiro tipo: o distribuído, que pode ser descrito como "conectivo", assim enunciado pelo autor: "A property of one entity must lead to or become a property of another entity in order for them to be considered connected; the knowledge that results from such connections is connective knowledge" (DOWNES, Stephen. An introduction to connective knowledge, 2005 . Disponível em: <https://www. downes.ca/cgi-bin/page. cgi? post $=33034>$. Acesso em:6 nov. 2018. conhecimento $^{42}$ é uma função da rede, que se torna, assim, um elemento cognitivo separado: processa, filtra, avalia e valida nova informação"43.

Após analisar as perspectivas postuladas por behavioristas, cognitivistas e construtivistas sobre o conhecimento/aprendizagem, Siemens retoma aspectos relativos ao conectivismo e explicita as diferenças e semelhanças.

\section{Quadro 1: Teorias da aprendizagem sistematizadas por George Siemens ${ }^{44}$}

\begin{tabular}{|c|c|c|c|c|}
\hline Propriedades & Behaviorismo & Cognitivismo & Construtivismo & Conectivismo \\
\hline $\begin{array}{l}\text { Como ocorre a } \\
\text { aprendizagem? }\end{array}$ & $\begin{array}{c}\text { Caixa preta } \\
\text { - enfoque no } \\
\text { comportamento } \\
\text { observável }\end{array}$ & $\begin{array}{l}\text { Estruturado, } \\
\text { computacional }\end{array}$ & $\begin{array}{l}\text { Social, sentido } \\
\text { construído por } \\
\text { cada aprendiz } \\
\text { (pessoal) }\end{array}$ & $\begin{array}{l}\text { Distribuído numa } \\
\text { rede, social, } \\
\text { tecnologicamente } \\
\text { potenciado, reconhecer } \\
\text { e interpretar padrões }\end{array}$ \\
\hline $\begin{array}{l}\text { Fatores de } \\
\text { influência }\end{array}$ & $\begin{array}{l}\text { Natureza da } \\
\text { recompensa, } \\
\text { punição, } \\
\text { estímulos }\end{array}$ & $\begin{array}{l}\text { Esquemas } \\
\text { existentes, } \\
\text { experiências } \\
\text { prévias }\end{array}$ & $\begin{array}{l}\text { Engajamento, } \\
\text { participação, } \\
\text { social, cultural }\end{array}$ & Diversidade da rede \\
\hline $\begin{array}{l}\text { Qual é o papel } \\
\text { da memória? }\end{array}$ & $\begin{array}{l}\text { A memória é } \\
\text { o inculcar de } \\
\text { experiências } \\
\text { repetidas } \\
\text { - onde a } \\
\text { recompensa e } \\
\text { a punição são } \\
\text { mais influentes }\end{array}$ & $\begin{array}{l}\text { Codificação, } \\
\text { armazenamento, } \\
\text { recuperação }\end{array}$ & $\begin{array}{l}\text { Conhecimento } \\
\text { prévio } \\
\text { remisturado } \\
\text { para o contexto } \\
\text { atual }\end{array}$ & $\begin{array}{c}\text { Padrões adaptativos, } \\
\text { representativos do } \\
\text { estado atual, existente } \\
\text { nas redes }\end{array}$ \\
\hline $\begin{array}{l}\text { Como ocorre a } \\
\text { transferência? }\end{array}$ & $\begin{array}{l}\text { Estímulo, } \\
\text { resposta }\end{array}$ & $\begin{array}{l}\text { Duplicação dos } \\
\text { constructos de } \\
\text { conhecimento } \\
\text { de quem sabe } \\
\end{array}$ & Socialização & $\begin{array}{c}\text { Conexão (adição) com } \\
\text { nós (nodes) }\end{array}$ \\
\hline $\begin{array}{c}\text { Tipos de } \\
\text { aprendizagem } \\
\text { mais bem } \\
\text { explicados }\end{array}$ & $\begin{array}{c}\text { Aprendizagem } \\
\text { baseada em } \\
\text { tarefas }\end{array}$ & $\begin{array}{l}\text { Raciocínio, } \\
\text { objetivos } \\
\text { claros, } \\
\text { resolução de } \\
\text { problemas }\end{array}$ & $\begin{array}{c}\text { Aprendizagem } \\
\text { social } \\
\text { enfatizando } \\
\text { a interação } \\
\text { através da } \\
\text { observação }\end{array}$ & $\begin{array}{c}\text { Aprendizagem } \\
\text { complexa, núcleo que } \\
\text { muda rapidamente, } \\
\text { diversas fontes } \\
\text { de conhecimento. } \\
\text { É a integração } \\
\text { de princípios } \\
\text { explorados pelo } \\
\text { caos, rede e teorias } \\
\text { da complexidade e } \\
\text { auto-organização. A } \\
\text { aprendizagem é um } \\
\text { processo que ocorre } \\
\text { dentro de ambientes } \\
\text { nebulosos onde os } \\
\text { elementos centrais } \\
\text { estão em mudança - } \\
\text { não inteiramente sob o } \\
\text { controle das pessoas. }\end{array}$ \\
\hline
\end{tabular}

O conectivismo - ou aprendizado distribuído, conforme a contribuição de Downes ${ }^{45}$-, na síntese de Mattar, "é proposto então como uma teoria mais 
adequada para a era digital, quando é necessária ação sem aprendizado pessoal, utilizando informações fora do nosso conhecimento primário"46.

Tanto a questão das sucessivas mudanças quanto a de aprender também com o que está fora de nós são enfatizadas por Siemens e pelos autores que o citam. Antes disso, é bom frisar que o conectivismo é a integração de princípios explorados pelo caos, rede, complexidade e auto-organização. Contudo, a aprendizagem, conforme Siemens ${ }^{47}$, "é um processo que ocorre dentro de ambientes nebulosos em que os elementos centrais estão em constante mudança - não totalmente sob o controle do indivíduo". Aprendizagem (definida como conhecimento aplicado), para Siemens, "pode residir fora de nós mesmos (dentro de uma organização ou de um banco de dados)", e continua: "ela é focada em conectar conjuntos de informações especializadas, e as conexões que nos permitem aprender mais são mais importantes do que o nosso estado atual de conhecimento" ${ }^{48}$.

Mattar frisa a questão do potencial das conexões externas do conectivismo:

As teorias da aprendizagem deveriam ser ajustadas em um momento em que o conhecimento não é mais adquirido de maneira linear, a tecnologia realiza muitas das operações cognitivas anteriormente desempenhadas pelos aprendizes (armazenamento e recuperação da informação) e, em muitos momentos, o desempenho é necessário na ausência de uma compreensão completa. E a cognição e a aprendizagem são distribuídas não apenas entre pessoas, mas também entre artefatos, já que podemos descarregar trabalho cognitivo em dispositivos que são mais eficientes que os próprios seres humanos na realização de $\operatorname{tarefas}^{49}$.

\section{TEORIA ATOR-REDE (TAR) E A RESOLUÇÃO DE CONFLITOS}

Em matéria de raciocínio, podemos cruzar com o pensamento de Bruno Latour, do princípio para as consequências da TAR, ao fundamentar que "as redes constituem a vida social, não como estrutura que a enquadra, mas como relação que a inaugura. Tudo pode e deve ser visto como 'ator-rede", conforme resume $\operatorname{Lemos}^{50}$. Por trás de uma aparente individualização está "o movimento de rede de actantes e intermediários mobilizados na resolução de conflitos. Assim sendo, todo objeto (humano e não humano) é uma estabilização temporária de sua trajetória (subsistência e não substância). Individualidade e rede dinâmica que o constitui, afirma Latour" ${ }^{51}$.

As atividades dos atores consistem em fazer conexões e alianças com novos elementos de uma rede e, com isso, ser capazes de redefinir e transformar os componentes dessa rede (Callon, 1986, p. 93). [...] Os atores-actantes na TAR correspondem a quaisquer espécies de figuras dotadas da habilidade de agir, incluindo pessoas e objetos materiais: inscrições (quaisquer coisas escritas), artefatos técnicos, entidades sob estudo, conceitos, organizações, profissões, dinheiro etc. ${ }^{52}$

46.MATTAR, op. cit.

47. SIEMENS, 2004, p 5-6.

48. Ibidem.

49. Ibidem.

50. LEMOS, André Luiz Martins; RODRIGUES, Leonardo Pastor Bernardes. Internet das coisas, automatismo e fotografia. Revista Famecos. Porto Alegre v. 21, n. 3, p. 1016-1040, setembro-dezembro 2014. Disponível em <http://revistaseletro nicas.pucrs.br/ojs/index. php/revistafamecos/arti cle/download/.../12574> Acesso em: 16 abr. 2017.

51. Ibidem.

52. LATOUR, Bruno. Reagregando o social: uma introdução à teoria ator-rede. Salvador: EdUfba, 2012, p. 38. 
53. HOLANDA, 2014.

54. Ibidem.

55.LATOUR, Bruno et al. O todo é sempre menor que as partes: um teste digital acerca das mônadas de Gabriel Tarde. Tradução de Flávia Gonsales e Beatriz Redko. Parágrafo, v. 2, n. 3, jul./dez. 2015. Disponível em: <http://revista seletronicas.fiamfaam.br/ index.php/recicofi/article/ view/329/336>. Acesso em: 22 mai. 2016.

56. BANK, op. cit.

57. Ibidem.

58. SANTAELLA, op. cit.

59. Ibidem.

60. Ibidem

61. MOTA, José Carlos. Da Web 2.0 ao e-Learning 2.0: Aprender na rede. Dissertação de mestrado em Ciências da Educação, especialidade Pedagogia do e-Learning, Universidade Aberta, Portugal, 2009.

Disponível em: <http:// orfeu.org/weblearning20/>. Acesso em: 21 mai. 2015.
Derivado da semiótica greimasiana, o termo actante designa qualquer elemento atuante, seja este humano ou não humano, responsável por algum tipo de transformação no curso de ação dos outros elementos ${ }^{53}$. Humanos e não humanos representam a recusa em assumir formulações baseadas na oposição sujeito-objeto e todas as suas consequências negativas para as ciências ${ }^{54}$. A Teoria ator-rede "vem sendo apropriada de diversos modos pelas Ciências Humanas e Sociais, especialmente por pesquisas em que a tecnologia e a ciência ocupam lugares centrais" 55 .

Por outro lado, Bank torna claro como as ciências humanas têm a capacidade de interferir de forma importante no processo de aprendizagem. Elas "podem fazer mais do que nos ajudar a entender o que não deveríamos estar fazendo: elas podem nos ajudar a contemplar o que deveríamos fazer" ${ }^{56}$, acrescentam as funções caras das artes e também trazem a curiosidade à baila quando lembram que podemos estar "bem longe do mundo clássico que separava as artes liberais (artes liberales) das artes técnicas (artes serviles), mas as artes liberais ainda são indispensáveis porque fomentam a curiosidade intelectual e o desejo de aprender pelo prazer de aprender" ${ }^{27}$.

Razão tem Santaella ${ }^{58}$ ao nos lembrar que "todas essas inovações foram crescentemente entrando nos nossos lares, locais de trabalho, de educação e, com isso, começou a se formar um ambiente de tecnologias semânticas e cognitivas que, longe de se comportarem como ferramentas, tornaram-se partes do ambiente". Assim, acrescenta que "estamos habitando ecologias que estão saturadas dessas tecnologias, algumas delas adaptativas, na medida em que seus designs estão aptos a nos prover com o que necessitamos de acordo com o que somos e o que fazemos" ${ }^{59}$, e completa: "com isso, estão emergindo desafios de várias ordens; dentre os múltiplos desafios, os educacionais são os que mais urgentemente devem ser enfrentados" 60 .

Siemens é um dos teóricos que se debruçam a analisar e triangular as correntes de aprendizagem com a interdisciplinaridade ao juntar outras ciências ou disciplinas que possam ressaltar que "o crescimento exponencial do conhecimento, a investigação emergente (em neurociência e em inteligência artificial)", além das "novas filosofias do conhecimento (knowing), e a complexidade crescente, que requer um saber e uma interpretação distribuídos, já não encontram respostas suficientes nas grandes teorias da aprendizagem existentes" ${ }^{61}$.

A experiência de aprendizagem pode definir-se como o momento em que adquirimos, de forma ativa, o conhecimento que nos faltava para completarmos uma tarefa necessária ou resolvermos um problema. A aprendizagem é multifacetada, orientada e determinada pela tarefa.

Trata-se, no fundo, de trazer para a experiência de aprendizagem elementos que permitam ir além da sala de aula, do curso, de integrá-la na vida real, de modo que as pessoas, sobretudo nas áreas em que a informação se expande de forma acelerada, possam manter-se atualizadas. Não é nos cursos e nas instituições tradicionais que se podem encontrar essa adaptabilidade, 
autossuficiência e permanência do conhecimento (enquanto o aprendiz dele necessitar), mas, sim, numa noção de aprendizagem como uma ecologia, uma comunidade, uma rede ${ }^{62}$.

Os próprios espaços e estruturas da aprendizagem são os que se deslocam e transformam, diz Siemens; assumindo sua inspiração em nomes como Ivan Illich ou Paulo Freire, diz:

aspira-se a uma pedagogia da participação que leve a um afrouxamento da hierarquia institucional e a uma abertura e desdobramento da sala de aula em novas ecologias de aprendizagem (os seus espaços) onde comunidades e redes (as suas estruturas) possam florescer e sobrevir, assim, a diversidade, o diálogo e a participação ativa ${ }^{63}$.

Santaella enfatiza: "desenvolver estratégias integradoras para entrar no jogo das complementaridades com que as mídias atuais nos presenteiam constitui o grande desafio dos sistemas educacionais e curriculares no mundo contemporâneo" ${ }^{64}$. Mas o desafio maior que a aprendizagem ubíqua (livre, aberta), evidenciada pela autora,

traz aos sistemas de ensino é a pressão que ela causa sobre o papel tradicional do professor, que, agora, mais do que nunca, está longe de ser o detentor do saber. Quando a aprendizagem se encontra em céu aberto, qualquer aprendiz pode trazer, para o mestre, informações que este não detém. Conclusão: novas modalidades de diálogo estão emergindo, para as quais o professor deve estar preparado na medida em que tiver a segurança serena em relação ao fato de que ficou no passado a era na qual costumava ser o detentor altissonante da transmissão e da transferência de conhecimento ${ }^{65}$.

Afinal, como lembra Santaella: "processos de aprendizagem abertos significam processos espontâneos, assistemáticos e mesmo caóticos, atualizados ao sabor das circunstâncias e de curiosidades contingentes" ${ }^{" 66}$.

Findamos esta breve reflexão sobre aprendizagem ativa com a rica ajuda de Siemens, dos autores que o estudam e dos demais autores; e chegamos finalmente à aproximação do caos como iniciamos este artigo. Mesmo porque, diz Siemens, o caos é uma nova realidade para quem trabalha com o conhecimento. A revista Science Week cita a definição de Nigel Calder de que o caos é "uma forma crítica de ordem. O caos é a ruptura da previsibilidade, evidenciada em arranjos complicados que inicialmente desafiam a ordem" ${ }^{\circ}$ e faz paralelo mostrando que, ao contrário do construtivismo, em sua afirmação de que os alunos tentam promover a compreensão através de tarefas de criação de significado, "o caos afirma que o significado existe - o desafio do aluno é reconhecer os padrões que parecem estar escondidos. Significar e formar conexões entre comunidades especializadas são atividades importantes" ${ }^{\text {. }}$.

Assim, propomos aplicar no dia a dia as ações, transcrições, interações com nossos estudantes-atores-rede, assim como nós, que não paramos de estudar, para que possamos junto adquirir novas lições de jornalismo servindo para o resto da vida.
62 SIEMENS, George. Learning ecology, communities, and networks: extending the classroom. In: HUG, Theo (ed.). Didactics of microlearning: concepts, discourses and examples. New York: Wasmann Verlag, 2003.

63. Ibidem

64. SANTAELLA, Lucia. Comunicação ubíqua: repercussões na cultura e na educação. São Paulo: Paulus, 2013, p. 6

65. SANTAELLA, op. cit.

66. Ibidem.

67. SIEMENS, op. cit., 2005.

68. Ibidem 
comunicação \& educação • Ano XXIII • número 2 • jul/dez 2018

\section{REFERÊNCIAS BIBLIOGRÁFICAS}

AKMANSOY, Vesili; KARTAL, Sadik. Chaos Theory and its Reflections on Education: Mehmet Akif Ersoy University Case. Educational Sciences: Theory \& Practice, v. 14, n. 2, p. 510-518, 2014. Disponível em: < https://files.eric. ed.gov/fulltext/EJ1038743.pdf>. Acesso em 24 jan. 2018.

BANK, James. A morte das ciências humanas vai matar também as exatas. Disponível em: <http://pt.aleteia.org/2016/01/26/a-morte-das-cienciashumanas-vai-matar-tambem-as-exatas-2/?ru=b4127ec0c12e59207195a9bc32e 85f72>. Acesso em: 18 set. 2016.

BARBOSA, Eduardo Fernandes; MOURA, Dácio Guimarães. Metodologias ativas de aprendizagem na educação profissional e tecnológica. Boletim Técnico do Senac, Rio de Janeiro, v. 39, n. 2, p. 48-67, 2013.

BECKER, Beatriz. Vida na mídia: além do jornalismo. Entrevista com Mark Deuze. Revista Eco Pós, v. 1, n. 19, 2016. Disponível em: <https: / / revistas.ufrj. br/index.php/eco_pos/article/view/3354/2629>. Acesso em: 12 nov. 2016.

BROWN, John Seely. Growing up digital: Como as mudanças na web funcionam, educação e as formas de aprendizagem das pessoas. Associação de Ensino a Distância dos Estados Unidos, 2002. Disponível em: <http:// www.usdla.org/html/journal/FEB02_Issue/article01.html>. Acesso em: 25 jan. 2016.

Fractal Foundation. What is chaos theory? Disponível em: <http:// fractalfoundation.org/resources/what-is-chaos-theory/>. Acesso em: 23 jan. 2018.

HOLANDA, André. Traduzindo o jornalismo para tablets com a Teoria Ator-rede. 2014. Tese (Doutorado em Comunicação Social) - Universidade Federal da Bahia, Salvador, 2014. JONASSEN, David. Computadores, ferramentas cognitivas: desenvolvendo o pensamento crítico nas escolas. Porto/Portugal: Porto Editora, 2007. (Coleção Ciências da Educação Século XXI, n. 23.)

LATOUR, Bruno. Reagregando o social: uma introdução à teoria ator-rede. Salvador: EdUfba, 2012.

LATOUR, Bruno et al. O todo é sempre menor que as partes: um teste digital acerca das mônadas de Gabriel Tarde. Tradução de Flávia Gonsales e Beatriz Redko. Parágrafo, v. 2, n. 3, jul./dez. 2015. Disponível em: <http:// revistaseletronicas.fiamfaam.br/index.php/recicofi/article/view/329/336>. Acesso em: 22 mai. 2016.

LEMOS, André Luiz Martins; RODRIGUES, Leonardo Pastor Bernardes. Internet das coisas, automatismo e fotografia. Revista Famecos, Porto Alegre, 
v. 21, n. 3, p. 1016-1040, set.-dez. 2014. Disponível em: <revistaseletronicas. pucrs.br/ojs/index.php/revistafamecos/article/download/.../12574>. Acesso em: 16 abr. 2017.

MATTAR, João. Aprendizagem em ambientes virtuais. Revista Teccogs, n. 7, jan./jun. 2013. Disponível em: <http://www.pucsp.br/pos/tidd/teccogs/ $\operatorname{artigos} / 2013 /$ edicao_7/2-aprendizagem_em_ambientes_virtuais-joao_ mattar.pdf $>$. Acesso em: 17 out. 2016.

MORA, Francisco. Francisco Mora: "É preciso acabar com o formato das aulas de 50 minutos”. Entrevistadora: Ana Torres Menárguez. El País, Madri, 23 fev. 2017. Disponível em: <http://brasil.elpais.com/brasil/2017/02/17/ economia/1487331225_284546.html>. Acesso em: 23 fev. 2017.

PERNIOLA, Mario. Do sentir. Tradução de Tom Guerreiro. Lisboa: Editorial Presença, 1999.

SANTAELLA, Lucia. Comunicação ubíqua: repercussões na cultura e na educação. São Paulo: Paulus, 2013.

Curso de especialização em educação na cultura digital. Linguagens do Nosso Tempo. 1. ed. Brasília, DF/MEC, 2014. Disponível em: <http:// catalogo.educacaonaculturadigital.mec.gov.br/hypermedia_files/live/ linguagens_do_nosso_tempo/apresentacao.html>. Acesso em 12 dez. 2016.

SIEMENS, George. SIEMENS, George. Learning ecology, communities, and networks: extending the classroom. In: HUG, Theo (ed.). Didactics of microlearning: concepts, discourses and examples. New York: Wasmann Verlag, 2003.

. Conectivismo - uma teoria de aprendizagem para a idade digital. 12 dez. 2004. Disponível em: <http://usuarios.upf.br/ teixeira/livros/ conectivismo\%5Bsiemens\%5D.pdf>. Acesso em: 3 dez. 2016.

. Connectivism: a learning theory for a digital age. International Journal of Instructional Technology and Distance Learning, v. 2, n. 1, 2005. Disponível em: <http://www.itdl.org/Journal/Jan_05/article01.htm>. Acesso em: 18 fev. 2015.

Knowing knowledge, 2006. Disponível em: <http://www. elearnspace.org/KnowingKnowledge_LowRes.pdf>. Acesso em: 12 mar. 2015.

A world without courses, 2008. Disponível em: <http://www. elearnspace.org/media/worldwithoutcourses/player.html>. Acesso em: 16 jan. 2015.

VALENTE, José Armando. Blended learning e as mudanças no ensino superior: a proposta da sala de aula invertida. Educar em Revista, Curitiba, edição especial, n. 4, p. 79-97, 2014. 
